- Clark. YI. Adaptie frequenc-domain equalisation and diversity combining for broadband wireless communications". IEEE J. Sol flew Commm. 1998. 16.18), pp. $1385-1395$

S Whihara. K. et al: Comparison of SCFDE and OFDM with adaptivo modulation and coding in nonlincar fading channel: Electron. Lett. $200^{-} \cdot 43 \cdot(3)$. pp. $174-1^{-5}$

\section{High extinction switching of SOAs for in-band crosstalk reduction in PON}

C. Antony. G. Talli. P.D. Townsend. J. Baurelinck.

D.W. Smith and I. Lealman

\begin{abstract}
Burstmode operation in neve-gencration large-split. long-reach lo Goit s passire optical netwoths $P O$ S s poses challenging requirements on optical network unit oNli design. One critical requirement in high-split networks is to suppess the oxt off-state cmissions sufficienty to prevent penaltes arising from in-band crosstalk. Pronosed and demonstrated is the use of semiconductor optical amplifiers 150Ast to proxide this hish-extinction OXL gating function. A novel experimental tethrique for accurate characterisation of the dynumic extmetion introduced by the SOAs is deseribed. Which is baned on the bit error rate penalty indiced he the interterence from the Sof off-state emissions. The experimental resils indicate that the proposed ONL design can allow the operation of POSs with इ12-14arsplits.
\end{abstract}

Intrudution: Multi-wavelength. long-reach $1100 \mathrm{~km} 10$ Gbit s passive optical networks (POXs) that integrate access and metropolitan area networks into a single. low-cost. all-optical sstem are promising candidates for future broadhand access. The architecture enables a number of large-split. long-reach POXs. each working at different wavelengths to share the same backhaul fibre infrastructure using a dense wavelength division multiplexing (DWDM) wavelength plan. An example of such a network. Which is currently being studied under the $E L$ project PIE\1AY has 32 downstream and 32 upstream watelengths on a 50 GH\% grid in a pure (-band DVDDM scheme and aims to support 51 2 customers per wavelength [1]. One of the major research challenges posed by these next generation PONs is the requmement for new 10 Gbit s transmission technologies. which must operate in burst mode. in order to allow time-sharing of the arailable upstream bandwidth between customers using time division multiple access. and also be compatible with DWDML upcration.

I her issue that arises from the burst-mode traffic in the upstream path of the POXs is the potential for interference between the actice customer optical network units (ONLs) and the off-state emissions from the inaetive OXLs at the same wavelength [2]. If the OXL off-state emission is not sufficionty suppressed. large interference penalties or eren crror floors ean be generated at the upstream receiver. This sets a maximum limit on the aggregate oft-state power. which is giren by the sum of all off-state powers of the inaetive users. To support a high number of wsers within a single network. Which is desirable for economic reasons. aach $O X L$ is required to achieve extremely low power levels in the off-state. In the conventional gigabit POX (GPOX) systems the OXL lasers are tumed off between bursts using a fast sw itching of the bias and madulation current and a DC-coupled interface [3]. However. this approach poses great challenges in networks such as PIE.M.X. which use DUDDM. since rapid tuning and locking of the laser wave length within the available $25 \mathrm{~ns}$ inter-burst guard bands is required Hence altemative solutions are preferred in which the operating conditions of the lasers are maintained constant between bursts. This Letter introduces the concept of using high-extinction electro-ontio switching of semiconductor optical amplifiers 150 . 1 s) as a gating tech niqus in the OXLs to reduce the eftect of in-band crosstalk. Although the SOA gating in POXs has been proposed before [1]. to the best of our know ledge. the high-sped gating performance of this scheme hats never been experimentall tested. Here we describe for the first time a nowel experimental technique for accurate characterisation of the dinamic extinction introduced by the SOP gating.

Experiments and discasion: Fig. la shows the structure of a new. lowcost. hybrid-integrated. tunabla OXL transmitter that is eurrently under development within the PIE Y A.X protect [1]. The OXL transmitter comprises a tunable laser diode. an electro-absorption modulator

(EAM) and an SOA. While the EA.M is emplosed for low-chirp. high-speed modulation at 10 Gbits. the SOA is required to compensate for the power loss due to the EAMI and obtain a high output power 1-5 $\mathrm{ABm})[1]$. Tuming off the F.A.1 I does not solve the in-band crosstaik problem as this can only provide around $10 \mathrm{~dB}$ extinction. Instead. electro-optic switching of the SOA must be employed to provide sufficient suppression of the ONLs optical output power in the inactive state. Static characterisation of a conmercially arailable discrete SOA (CIP SOA-S-OEC-1550) shows that $>50 \mathrm{~dB}$ extinction, defined as the ratio between the power at the nominal bias current of $100 \mathrm{~m}$. the measured power. is achievable with the present technology (Fig. 1b). This level of extinction is in principle sufficient to allow a POX with more than 256 usets to operate with negligible levels of inband crosstalk [H]

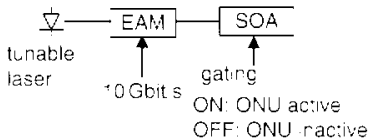

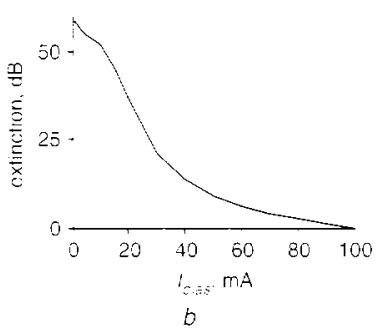

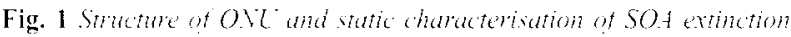
a Structure of $\mathrm{ONL}$

b Static characterisation of $\mathrm{SO} A$ cxtinction

While the static off-state power of the SOA is sufficiently low to sustain a high number of users the dymanic behaviour could be affected by the transient response of the SOA. Although the $10.90^{\circ}$ orise and fall times of these SOAs are less than 1 ns and thus much shorter than tho inter-burst guard band 125 ns): even low levels of power due to long tails following the turn-off transient could still introduce significant levels of noise in following packets. A direct measurement of the SOA dynamic attenuation using, for example. a photodiode and an oscilloscope is not possible as the off-state power of the SOA is below the minimum sensitivity levels of the instrument. Hence we developed a novel way to characterise the drnamic extinction based on the bit error rate (BER) penalty induced by the interference from the SOA off-state emission.

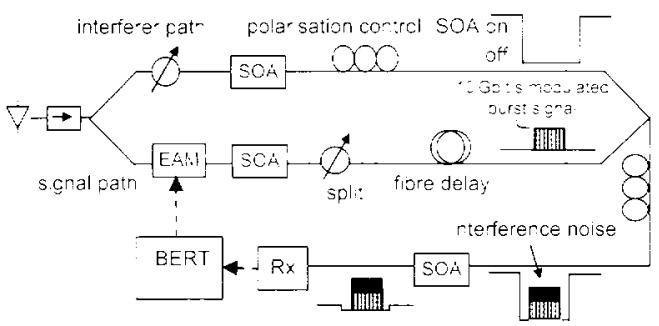

Fig. 2 tiperintintal still?

Fig. 2 shows a Mach-Zehnder system used for measuring the affect of interference from controlled amounts of SOA off-state emission where the OXL's are emulated using diserete components and a DFB instead of an integrated tunable laser. The SOAs used in the cxperiments aro high gain $(20 \mathrm{~dB})$. low noise figure $(? \mathrm{~dB})$ with $>8 \mathrm{dBm}$ saturated output. The devices are optimised for low bias current operation ( 100 m.A) to enable fast electrical switching with conmercial somiconductor laser drivers. One path is regarded as the signal and the other the interferer. The attenuator denoted as 'split' in the Figure adjusts the power level of the signal arm to smulate the effect of the off-state emission from 511 inactive ONLs interfering with the signal generated by one active OXL. The fibre delas lins in the signal arm ensures that the optical path difference between the two ams exceds the coherence length of the $50 \mathrm{MHz}$ linewidth DFB laser. Polarisation controllers were adjusted to ensurs that the two paths had identical polarisation. which would comespond to tho highest level of interference noise and henee the worst-case situation in an actual network. Light in the signal arm was modulated using an EAM to 10 Gbit s bit rate with burst packets each consisting of three blocks of $2^{-}-1$ 112? bits) pseudorandon bit sequence (PRBS) 
IFig. 3 insetı. Burst signal and burst interferer pachet invelopes were generated by gating the SOAs appropriately using a pulse generator. During the on-state the SOAs were biased at 100 m.1 to proside an arerage output power of $-5 \mathrm{dBm}$ and then switched to a suitable low bias current value to emulate optical power leakage when an ONL is in the off-state. To avoid receiver overtoad. a third gating SOA was placed before the receiver to suppress the high power on-state light from the interferer arm and allow only the simnal packets to pass through. The high split ratio emulated leads to low input power levels at the third gating SOA reducing the optical signal to noise ratio to $25 \mathrm{~dB}$. which introduces $\sim 0.5 \mathrm{~dB}$ penalty at BER $10^{\circ}$. The penalts is however. identical in all measurements and hence does not affect the estimation of the in-band crosstalk effect. The BER was measured selectively in the signal bursts at the receiver using the error-location capability of a 12.5 Cibit s digital error analser (BERTSCOPE $12500 \mathrm{~A}$

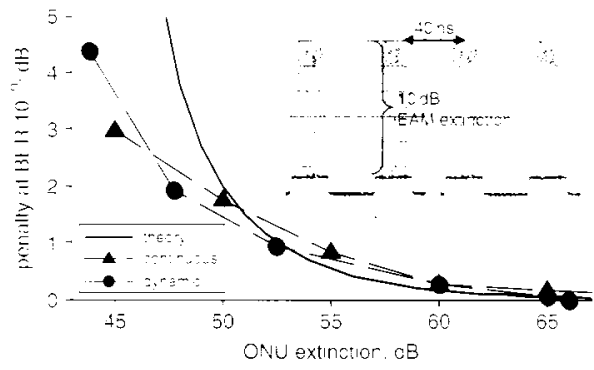

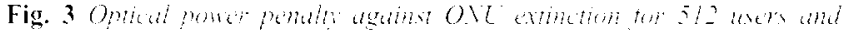
vishal pachet thice

To deduce the performance degradation due to the dumamic behaviour of the SO Ss. a comparison should be made sith characterisation results obtained when the ONL operates in continuous mode. The same setup and experimental procedures were used in the case of continuous mode characterisation except that the SOAs were not gated and a $2^{-}-$I PRBS was used. The SOAs in both arms were operated at constant bias currents. with a fixed $100 \mathrm{~m}$. corresponding to the OXL on-state and a suitahli low bias current value for the SOA in the interferer arm.

The crosstath penalty induced is ploted against the OXL extinction in Fig. 3 for continuous mode and dynamic characterisation. The different levels of extinction have been obtained by changing the off-state bias current of the SOA according to static characterisation of the device (Fig. 1h. Continuous mode characterisation of constalk penalty for different network applications has been experimentally investigated prevously [5] and the results are in agreement with the current measurements. Fig. 3 also shows the penalts predicted by theors. calculated using a standard model of heat noise caused by multiple crosstalk [5]. There is good agrement with the experiments. considering that the theory assumes Gaussian statistics. which is a valid assumption for a large number of uncomelated interferers. while in the experiments there is only one interferer. causing the slightly lower measured penalties [5]. It is. however. important to note that in a real network implementation the Gaussian assumption is valid owing to the large number of interferers.

The comparisom of continuous mode and disnamic behar iour allows the quality of the SOA transient response to be evaluated. Any extra impairment induced by the dymamic gating of the SOA would be represented as an additional penalty compared to the continuous mode characterisation curve. The results show that this is not the case. since no extra penalty has been induced by the drmamic switching of the SOA. The maximum extinction obtained by gating the SOA used in the current $O . \mathrm{XL}$ design is $6 ? \mathrm{~dB}$. This extinction corresponds to a negligible $<0.1 \mathrm{~dB}$ power penalty indicating that this is sufficient to allow the operation of hong-reach POXs with 512 users. if all interferers encounter the same loss as the signal [2].

Concham: i nowel experimental technique to characterise the dynamic extinction of $50 \mathrm{As}$. used for OXL gating in next-generation POAs is presented. The echnique is based on burstmode measurement of the BER penalty induced by the interference from the SOA off stitti emission. The disorete SOAs used in the current OXL design can be effectively gated to proside a maximum $O N L$ extinction of $6 ? \mathrm{~dB}$.
Lnder these operating conditions the experimental interference penalties due to in-band crosstalk are negligible. Which suggests the feasibility of this OXL approach for long-reach POXs with up to 512 users.

thenouledgments: This work was supported by Science Foundation lreland under grant number 06 IN [969. and by the European Commission under project PIE.MAX.

The Institution of Engineering and Technology 2008 $1^{-}$- April ? 2 (1)

Electronics Letters online no: 20081095

doi: 10.1049 el:20081095

C. Anons. G. Talli and P.D. Townsend (Tindall Natonal Institure and Department of Phisics. Photonic Sistems Group. Linversin College Cork. Cork Ireland)

E-mail: cleitus antony à tyndall.ie

I. Bauwelinch (INTEC IMEC. Ghem Linversin: Sint-Pietersniemstrat 4. Gont gout). Belgitm)

D.W. Smith and I. Lealman ICIP. Adwtral Parh. Martlesham Heath Ipswich IP: 3RE. (inited Kingdom)

\section{References}

I Talli. C.. Chow C. IV. Townsend. P.. Daver. R. De Ridder. T. Oiu. XZ Ossieur. P.. Krimmel. H.G.. Smith. D.. Lealman. I.. Poustie. A.. Randel. S.. and Rohde. H.: "Integrated metro and access nerwork: PIEMAN" Proc. 1OC. July 2007. Sweden

2 Backelandt. B.. Mélange. C. Bauwelinck. J.. Ossieur. P.. De Ridder. T. Qiu. X.Z.. and Vandewege. J.: OS.VR penalty imposed by linear in-band crosstalk caused by interburst residual power in multipoint-to-point networks. IEEE Photenies Techol. Lett. 2008. 20. (8). pp. $587-589$

3 Bauselinck. J. Chen, W. Verhulst. D. Martens. Y. . Ossicur. P. Qiu. X.Z. and $\backslash$ andewege. J.: A high-resolution burst-mode transmitter with fast and accurate optical level monitoring for a 1.25-Gh s upstream POX'. IEEE J. Solid-Sute Circuits. 2005.40 .161 . pp. 1322-1330

4 Yang. S.. and Yao. J.G.: 'Impact of erosstalk induced beat nosse on the size of semiconductor laser amplifier based optical space switch structures:. IEEE Photonics Technol. Lett. 1996. 8. (7) pp. 894-896

- Takahashi. H. Oda. K.. and Toba. H.: 'Impact of erosstalk in an arraved

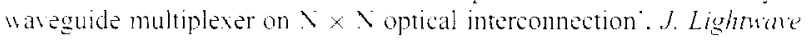
Tectimol. 1996. 14. (6). pp. 109--1105

\section{Quantum dash actively modelocked Fabry-Perot laser module demonstrated as part of wavelength tunable $R Z$ transmitter}

G. Girault. M. Gay. S. Lobo. L. Bramerie. M. Joindot. J.C. Simon. A. Shen. F. Blache. H. Gariah. F. Mallécot. O. Le Gouezigou. F. Poingt. L. Le Gouezigou. F. Pommereau. B. Rousseau. F. Lelarge and G.-H. Duan

\footnotetext{
A quantum dash Fabry-Perot actively modelocked laser moduk is tested as part of a +2.? Gbit stransmitter with more than $10 \mathrm{~nm}$ waselongth tunability. Its low chimp level is also assessed through chromatio dispersion tolerance measurements.
}

Imroduction: Modelocked laser diodes (MLLDs) have a great potential for many applications in optical communications. such as optical timedivision multiplexing [1] or optical clock recovery [2. 3]. Furthermore. multi-warelength lasers have become attractive as they enable one to obcain a large number of warelength-division-multiplexing (WDM) channels from a single souree [4. 5]. Future WDM light sources must meet a number of criteria such as simple and stable operation. cost effectiveness and low energy consumption. Quantum dash (QD) Fabr-Perot (FP) MLLDs are promising candidates as the meet all the abore criteria. In addition these components have a small footprint. hold possibilities for monolithic integration and have recently show the possibility to generate short pulses over a wide spectral bandwidth through passive filtering [6]. This last reference deals with spectral and temporal characterisations performed thanks to the linear spectrogram method [7].

In this Letter. a 42.7 Gbit s RZ transmitter using the QD FP MLLD module is assessed thanks to bit error rate (BER) measurements. and its chirp is evaluated through chromatic dispersion tolerance investigations. 


\section{Contents}

ANTENNAS \& PROPAGATION

$2 \times 2$ etched slot array with corporate slotline feed network

J. Joubert and J.W. Odendaal (South Africa)

Compact dual-band printed monopole antenna for WLAN application

H. Ma, O.-X. Chu and O. Zhang

(People's Republic of China)

Defected ground structure to reduce mutual coupling between cylindrical dielectric resonator antennas

D. Guha, S. Biswas, T. Joseph and M.T. Sebastian (india)

Dual-resonant II-shape with double L-strips PIFA for implantable biotelemetry

C.-M. Lee, T.-C. Yo, F.-J. Huang and C.-H. Luo

(People's Republic of China)

\section{BIOMEDICAL TECHNOLOGY}

Improved algorithm of continuous abdominal

pressure using surface EMG
C.G. Song, K.S. Kim, J.H. Seo (Korea) and

J.U. Kang (USA)

Low-power and area-efficient PSK demodulator for wirelessly powered implantable command receivers

C.-S.A. Gong, M.-T. Shiue, K.-W. Yao and

T.-Y. Chen (People's Republic of China)

\section{CIRCUIT THEORY \& DESIGN}

Causal and stable reduced-order model for linear high-frequency systems

$M$. Condon, G. Grahovski (/reland) and

D. Deschrijuer (Belgium)

FIBRE OPTICS

$\mathrm{C}+$ L-band hybrid amplifier using FBGs for dispersion compensation and power equalisation S. K. Liaw and Y.-S. Huang (People's Republic of Chinal

Strong photoinduced Bragg gratings in arsenic selenide optical fibre using transverse

holographic method

G.A. Brawley, V.G. Ta'eed, J.A. Bolger (Australia),

J.S. Sanghera, I. Aggarwal (USA) and

B.J. Eggleton (Australia)

IMAGE PROCESSING

3D object retrieval approach based on directed acyclic graph lightfield feature

Q.K. Xiao, Q.H. Dai (People's Republic of China)

and H.Y. Wang (Singapore)

Fast mode decision algorithm for H.264 using statistics of rate-distortion cost

S. H. Kim and Y.-S. Ho (Korea)

Foreground segmentation based on selective foreground model

$X$. Zhang and J. Yang (People's Republic of China)

INSTRUMENTATION \& MEASUREMENT

Alternative approach to dynamic $I \mathrm{~V}$

characterisation of microwave FETs

E. Limiti, A. Nanni, A. Serino and F. Giannini (Italy)

Linearity of terahertz time-domain spectrometers M. Naftaly, M. Stringer and R.A. Dudley

United Kingdom!

INTEGRATED CIRCUITS

Linearity enhancement technology for mixer in monolithic CMOS UHF RFID interrogator

R.-X. Zhang, C.-Q. Shi and Z.-S. Lai

843

INTEGRATED OPTICS

Buried annealed/proton-exchanged $\mathrm{LiNbO}_{3}$ waveguides fabricated by direct bonding

technique

M. Fujimura, K. Beniya and T. Suhara (Japan) silicon nanomembranes on glass substrates

H. Yang, H. Pang, Z. Qiang, Z. Ma and

W. Zhou (USA)

LASERS

Relative intensity noise measurements of $5 \mu \mathrm{m}$ quantum cascade laser and $1.55 \mu \mathrm{m}$ semiconductor laser

Y. Takagi, N. Kumazaki, M. Ishihara, K. Kasahara

A. Sugiyama, N. Akikusa and T. Edamura (Japan)

\section{MICROWAVE TECHNOLOGY}

Broadband SiGe HBT Gilbert downconverter with 1.8 to $36 \mathrm{GHz}$ integrated dual Marchand balun

J.-S. Syu, C. Meng and S.-W. Yu

(People's Republic of China)

Continuous-wave terahertz system with electro-optical terahertz phase control

T. Göbel, D. Schoenherr, C. Sydlo, M. Feiginov,

P. Meissner and H.L. Hartnagel (Germany)

Reducing electrical size of metamaterial elements: simulations and experiments

T. Hao, C.J. Stevens and D.J. Edwards

(United Kingdom)

Waveguide-to-planar circuit transition for millimetre-wave detectors

G. Yassin, P.K. Grimes, O.G. King and C.E. North (United Kingdom)

MOBILE COMMUNICATION

Unequal protection using adaptive burst profile selection for WIMAX video streaming

R. Razavi, B. Tanoh, M. Fleury and M. Ghanbari (United Kingdom)

OPTICAL COMMUNICATION

1.25 10.3 Gbit/s dual-rate burst-mode receiver

K. Hara, S. Kimura, H. Nakamura, K. Nishimura,

$M$. Nakamura, N. Yoshimoto and $M$. Tsubokawa

(Japan)

Frequency-domain equalisation for optical transmission systems

K. Ishihara, T. Kobayashi, R. Kudo, Y. Takatori,

A. Sano, E. Yamada, H. Masuda and Y. Miyamoto (Japan)

849

High extinction switching of SOAs for in-band crosstalk reduction in PON

C. Antony, G. Talli, P.D. Townsend (treland),

J. Bauwelinck (Belgium), D.W. Smith and

1. Lealman (United Kingdom)

Quantum dash actively modelocked Fabry-Perot laser module demonstrated as part of wavelength tunable $R Z$ transmitter

G. Girault, M. Gay, S. Lobo, L. Bramerie

M. Joindot J.C. Simon, A. Shen, F. Blache

854 H. Gariah, F. Mallécot, O. Le Gouezigou, F. Poingt,

L. Le Gouezigou, F. Pommereau, B. Rousseau,

F. Lelarge and G.-H. Duan (France)

OPTICAL DEVICES \& MATERIALS

Tiled-aperture coherent beam combining using optical phase-lock loops

W. Liang, N. Satyan, A. Yariv, A. Kewitsch and 